doi: $10.12957 /$ childphilo.2018.36038

\title{
concepções de infância e a educação das crianças da classe trabalhadora: uma crítica benjaminiana ao projeto escola sem partido
}

\author{
luciana helena monsores ${ }^{1}$ \\ universidade do estado do rio de janeiro, brasil \\ ligia maria leão de aquino ${ }^{2}$ \\ universidade do estado do rio de janeiro, brasil
}

resumo

No presente artigo procuramos sistematizar algumas contribuições do filósofo Walter Benjamin na intenção de nos ajudar a pensar as infâncias e a educação da classe trabalhadora no contexto em que se formulam projetos de lei como o Escola Sem Partido, no Brasil. São projetos elaborados nos últimos anos, de forte cunho conservador e de controle ideológico. Buscamos em Benjamin a noção de experiência e como ela se situa na infância e na área da educação, bem como as suas contribuições no que se refere à educação popular ou proletária. A partir de tais noções e referencial benjaminiano, visamos analisar propostas educativas e projetos de lei, como o acima mencionado, indagando sobre as concepções de infância, história, experiência e política que atravessam esse debate. A intenção aqui é pensar sob uma ótica benjaminiana o crescimento das ideias que norteiam o projeto Escola Sem Partido e a sua influência na educação das crianças pequenas, em especial, das crianças da classe trabalhadora. Para tanto, consideramos escritos do autor como: Experiência e Pobreza, A vida dos estudantes, Teatro Infantil Proletário, Pedagogia Comunista, O narrador e suas narrativas radiofônicas apresentadas em rádios de Berlim e Frankfurt, nas quais a cultura e o cotidiano das crianças berlinenses têm destaque. Para começarmos a trilhar os caminhos desse estudo que se inscreve numa pesquisa de doutorado, em curso, além de Walter Benjamin, também recorremos a publicações de Gaudêncio Frigotto e de Jorge Larrosa Bondía, tendo ainda o projeto de lei federal n ${ }^{\circ}$ 193/2016 (Escola Sem Partido) como documento legal analisado.

palavras-chave: escola sem partido; infância; experiência.

\section{concepciones de infancia y la educación de los niños de la clase trabajadora: una crítica benjaminiana al proyecto escuela sin partido}

resumen

En el presente artículo buscamos sistematizar algunas contribuciones del filósofo Walter Benjamin con la intención de pensar las infancias y la educación de la clase trabajadora en el contexto en que se formulan proyectos de ley, como Escuela Sin Partido, en Brasil. Son proyectos elaborados en los últimos años, que guardan un fuerte cuño conservador y de control ideológico. Buscamos en Benjamin la noción de experiencia y cómo ésta entra en relación con la infancia y el área de la educación, así como sus contribuciones en lo que se refiere a la educación popular o proletaria. A partir de dichas nociones de la filosofía benjaminiana, analizamos propuestas educativas y proyectos de ley, como el mencionado, indagando sobre las concepciones de infancia, historia, experiencia y

\footnotetext{
${ }^{1}$ E-mail: lumonsores.uerj@gmail.com

2E-mail: ligiaaquino@yahoo.com.br
} 
concepções de infância e a educação das crianças da classe trabalhadora: uma crítica benjaminiana ao projeto escola sem partido

política que atraviesan ese debate. La intención aquí es pensar bajo una óptica benjaminiana el crecimiento de las ideas que orientan el proyecto Escuela sin Partido y su influencia en la educación de los niños pequeños, en especial, de los niños de la clase trabajadora. Con ese fin, apelamos a escritos del autor como: Experiencia, Experiencia y Pobreza, La vida de los estudiantes, Teatro Infantil Proletario, Pedagogía Comunista, El narrador y sus narrativas radiofónicas presentadas en radios de Berlín y Frankfurt, en las que se destaca la cultura y la vida cotidiana de los niños berlineses. Para empezar a recorrer los caminos de este estudio, que se inscribe en una investigación de doctorado en curso, también se recurre a las publicaciones como Gaudencio Frigotto y Jorge Larrosa Bondía, considerando el proyecto de ley federal no 193/2016 (Escuela Sin Partido) como documento legal analizado.

palabras clave: escuela sin partido; infancia; experiencia.

\section{conceptions of childhood and the education of working class children: a Benjaminian critique of the school project without a party}

abstract

The present article attempts to systematize some contributions of the philosopher Walter Benjamin with the intention of helping us think about childhood and the education of the working class in a context in which are formulated law propositions like Escola Sem Partido (School Without Political Party), in Brazil. These are propositions with a strong conservative nature and ideological control that have been developed in recent years. We seek in Benjamin the notion of experience and how it relates to childhood and the field of education, as well as his contributions to popular or proletarian education. From these notions and Benjaminian referential, we aim to analyze education projects and bills, such as the one mentioned above, inquiring about the conceptions of childhood, history, experience and politics that underlie this debate. The intention here is to think, from a benjaminian point of view, the continuous growth and expansion of the ideas that guide the "Escola Sem Partido" bill and its influence on the education of young children, especially working class children. For this, we consider some of the author's writings as: Experience, Experience and Poverty, The Life of Students, Programe for a Proletarian Children's Theater, Communist Pedagogy, The Storyteller and his radio narratives presented in Berlin and Frankfurt radio stations, in which children's culture and everyday life stand out. In addition to Walter Benjamin, we also refer to publications such as Gaudêncio Frigotto and Jorge Larrosa and to federal bill 193/2016 ("Escola Sem Partido"), as legal document analyzed, in order to begin tracing the paths of this study, which is part of a current doctoral research.

keywords: escola sem partido; childhood; experience. 
concepções de infância e a educação das crianças da classe trabalhadora: uma crítica benjaminiana ao projeto escola sem partido

Assim não se necessita, mesmo em relação ao proletariado, daqueles milhares de palavrinhas com as quais a burguesia mascara as lutas de classes de sua pedagogia. Poder-se-á renunciar assim tanto às práticas "imparciais", "compreensivas", "sensíveis", como também às educadoras "cheias de amor pela criança".

Walter Benjamin

A atual conjuntura política e a crescente difusão de ideias de cunho autoritário e conservador têm exigido muitos esforços de setores mais progressistas da sociedade, no sentido de resistir e combater toda a sorte de retrocessos no que se refere a políticas sociais educacionais.

É neste contexto de crítica e resistência que se insere o presente trabalho. Nosso principal objetivo aqui é discutir criticamente o projeto Escola Sem Partido, suas concepções de infância e educação, a partir da nossa leitura sobre algumas ideias e obras de Walter Benjamin. Os escritos de Benjamin (2009; 2012) nos ajudam a analisar e compreender o referido projeto e seus impactos na infância e na educação das crianças oriundas da classe trabalhadora. Recorremos, em nossa análise, à noção de experiência trazida pelo autor e como ela se situa na infância e na área da educação, bem como as suas contribuições no que se refere à educação popular ou proletária.

Walter Benjamin, judeu alemão que viveu entre 1892 e 1940, a maior parte desse tempo na Alemanha, enfrentou as duas Grandes Guerras e a ascensão do nazismo. Nas palavras de Michel Löwy (2009), não se trata de "um pensador como os outros".

Estamos habituados a classificar os filósofos de acordo com seu caráter progressista ou conservador, revolucionário ou nostálgico. Benjamin escapa a essas classificações. Foi um crítico revolucionário da filosofia do progresso, um nostálgico do passado que sonha com o futuro, um romântico partidário do materialismo. É possível defini-lo como marxista, visto que reivindica o materialismo histórico, mas sua interpretação do pensamento de Marx - nutrida por leituras de György Lukacs e Karl Korsch - é original e heterodoxa. (LÖWY, 2009, p. 259).

A partir do movimento dialético do pensamento, Benjamin não recusa o materialismo dialético de Karl Marx e constrói uma teoria da modernidade, ou melhor, um modo historiográfico materialista dialético de compreender a modernidade. Isso pode ser visto em muitas de suas obras, quando articula suas ideias e críticas com o sistema capitalista ao abordar o conceito de trabalho e as questões de classe. 
concepções de infância e a educação das crianças da classe trabalhadora: uma crítica benjaminiana ao projeto escola sem partido

A intenção aqui, então, é buscar pensar sob uma ótica benjaminiana o crescimento das ideias que norteiam o projeto Escola Sem Partido e a sua influência na educação das crianças pequenas, em especial, das crianças da classe trabalhadora, considerando escritos importantes do autor como: Experiência (2009a), Experiência e Pobreza (2012a), A vida dos estudantes (2009b), Teatro Infantil Proletário (2009c), Pedagogia Comunista (2009d), O narrador (2012b) e as narrativas radiofônicas apresentadas por ele em emissoras de rádio de Berlim e Frankfurt (2015), nas quais a cultura e o cotidiano das crianças berlinenses têm destaque.

Para isso, na intenção de dar início aos caminhos a que se propõe este artigo, faremos análise documental do projeto de lei federal 193/2016 e dialogaremos com Walter Benjamin (2009, 2012), Fernando Penna (2017), Gaudêncio Frigotto (2017) e Jorge Larrosa Bondía (2002).

Nosso objetivo é articular as ideias de Walter Benjamin ao momento atual em que percebemos um levante de concepções e pautas conservadoras e autoritárias, como identificamos no projeto de lei (PL) federal nº 193/2016, mais conhecido como Projeto Escola Sem Partido, seus impactos na educação das crianças pequenas pertencentes à classe trabalhadora e seus pressupostos. Ainda que de um outro tempo histórico, as contribuições de Benjamin são muito atuais e é sobre elas que nos debruçamos e vislumbramos pistas para compreender e reagir a movimentos conservadores ou mesmo fascistas.

\section{Sobre o projeto Escola Sem Partido}

O Escola Sem Partido é um programa ou projeto, encaminhado ao senado brasileiro como PL 193/2016 ${ }^{3}$, que proíbe, segundo seus defensores, "doutrinação ideológica" por parte de professores e instituições de ensino. O projeto de lei visa determinar limites para a atuação de professores, impedindo que promovam suas crenças ideológicas e partidárias em sala de aula ou que incitem estudantes a participarem de protestos populares.

O referido programa, apresentado em projeto de lei, vem recebendo apoio de políticos, personalidades e entidades ligadas à direita, como o Movimento Brasil Livre (MBL) ${ }^{4}$ e o Instituto Liberal de São Paulo (ILISP) 5 . A maioria dos projetos (do Senado, da Câmara Federal, mas também de Assembleias Estaduais

\footnotetext{
3 Projeto de Lei do senador Magno Malta do Partido da República (PR), do Espírito Santo, um pastor evangélico e vinculado a pautas moralizantes. Além desse projeto há ainda outro PL, de $\mathrm{n}^{\circ}$ 867/2015, que tramita na Câmara dos Deputados, de autoria do deputado Izalci, do Partido da Social Democracia Brasileira (PSDB).

${ }^{4}$ Movimento político brasileiro que defende o liberalismo e o republicanismo, ativo desde 2014. Em seu manifesto, cita cinco objetivos: "imprensa livre e independente, liberdade econômica, separação de poderes, eleições livres e idôneas e fim de subsídios diretos e indiretos para ditaduras". O movimento está posicionado à direita do espectro político. Disponível em: https://pt.wikipedia.org/wiki/Movimento_Brasil_Livre, acesso em 26/3/2018.

${ }^{5}$ O ILISP é uma entidade que assim se define: "O ILISP é um think-tank liberal criada no dia $1^{\circ}$ de junho de 2014, na cidade de São Paulo, Brasil."; e proclamam: "Queremos que o Brasil tenha tanta liberdade econômica e social a ponto de nossa existência não ser mais necessária". Disponível em: http://www.ilisp.org/quem-somos/. Acesso em 26/03/2018.
} 
e Câmaras Municipais) tem como característica a sua vinculação com segmentos religiosos evangélicos e católicos. O movimento em torno deste projeto afirma que existe um processo de doutrinação ideológica de cunho "esquerdista" muito forte nas escolas, e para interrompê-lo seria necessário limitar e intervir no trabalho docente e no currículo escolar, entendidos como doutrinadores. No bojo do que é identificado como pensamento "esquerdista" que visa "destruir" a família brasileira, seus autores apontam o perigo da abordagem da temática de gênero nas escolas ou qualquer crítica ou contestação social e política do sistema capitalista.

Essa pauta relacionada acima está presente em ações de vigilância e denúncia de professores, escolas e universidades do país. Na etapa da Educação Infantil, o movimento Escola Sem Partido tem atuado, principalmente, no que se refere ao controle quanto a possíveis abordagens sobre orientação sexual e de gênero, o que eles denominam como "ideologia de gênero", acreditando que professores influenciam ou até "escolhem" o gênero das crianças.

Os críticos ao programa afirmam que o mesmo representa uma grave ameaça à liberdade de expressão e a imposição de pensamento único. Mais do que isso: representa um discurso de uma neutralidade falaciosa, pois, como já afirmava Paulo Freire (2011), não existe imparcialidade, pois todos somos orientados por uma base ideológica. A grande questão, para ele, é se essa base ideológica é inclusiva ou excludente.

Em nosso primeiro levantamento, observamos que as ideias do Escola Sem Partido tiveram grande repercussão e difusão, principalmente, no segmento de pais, mães e responsáveis de alunas e alunos. Eles são recrutados como os grandes "fiscais" do trabalho do professor e são instigados a lutar veementemente contra qualquer rastro de "doutrinação ideológica" de esquerda nas escolas, e que parte dessas ações de convencimento tem sido dada através de igrejas cristãs (evangélicas e católicas).

Esse discurso tem se alastrado e conquistado grandes massas. Isso porque o programa Escola Sem Partido e seus adeptos utilizam uma "linguagem próxima do senso comum, recorrendo a dicotomias simplistas que reduzem questões complexas a falsas alternativas", através de quatro elementos principais: (1) a defesa do poder total dos pais sobre os filhos; (2) uma concepção de escolarização; (3) uma desqualificação do professor e (4) estratégias discursivas fascistas. (PENNA, 2017, p. 35).

A partir desses elementos trazidos por Penna (2017) e através das contribuições de Benjamin $(2009,2012)$, organizamos nosso entendimento e crítica destacando quatro pontos presentes nas obras do filósofo que podem nos ajudar a pensar sobre o assunto: (1) a concepção de experiência em Benjamin como discurso de autoridade e superioridade do adulto sobre a criança; (2) a criança como sujeito histórico, político e produtor de cultura, (3) a crítica de Benjamin ao sistema capitalista e a pobreza da experiência resultante do sistema financeiro e do estilo de vida burguês e (4) a concepção burguesa de educação. 
concepções de infância e a educação das crianças da classe trabalhadora: uma crítica benjaminiana ao projeto escola sem partido

\section{Infância, educação, experiência e a pobreza da experiência}

Geralmente, entende-se experiência como algo relacionado ao método científico ou todo e qualquer conhecimento ou aprendizado obtido por meio dos sentidos e das vivências ${ }^{6}$. Entretanto, é bem verdade que existem alguns conceitos filosóficos de experiência desenvolvidos por pensadores, além do próprio Benjamin (2009a; 2012a), como Agamben (2008), Foucault (1984, 1999) e Deleuze $(1988,2001)$. Em Walter Benjamin (2009a) a noção de experiência apresenta um entendimento peculiar e esse entendimento nos ajuda a pensar as infâncias como etapa geracional e a criança enquanto sujeito histórico de direitos e produtora de história e cultura, já que a criança é protagonista de suas próprias experiências inerentes à infância.

A noção de experiência em Benjamin $(2009,2012)$ aparece, principalmente, nas obras Experiência (2009a), Experiência e pobreza (2012a) e O narrador (2012b). A experiência em seus escritos é trazida através (1) da experiência a partir da própria infância, da narrativa de uma infância urbana, berlinense, a experiência como vivências significativas e, por outro lado, (2) do conceito de experiência na modernidade e a negação da sua possibilidade com o desenvolvimento acelerado da técnica, com o discurso da experiência como discurso de autoridade. Assim, para ele, falar de experiência significa falar de uma experiência com o mundo moderno e suas transformações.

Lessa (2016) afirma que a experiência benjaminiana relaciona-se com a memória, com o que é passado de geração em geração, com o que tem o peso da tradição e que, por se situar no âmbito da transmissão geracional, nos permite relacionar seu conceito com a educação. Para Benjamin (2012a), a experiência é a transmissão de histórias pela narração:

Ela sempre fora comunicada pelos mais velhos aos mais jovens. De forma concisa, com a autoridade da velhice, em provérbios; de forma prolixa, com a sua loquacidade, em histórias; às vezes como narrativas de países longínquos, diante da lareira, contadas a filhos e netos. (BENJAMIN, 2012a, p. 123)

Benjamin também traz a experiência como máscara do adulto, a qual intimida e destrói o que poderia ser construído na infância e desvaloriza os anos que as crianças e jovens estão vivendo. Essa experiência apresenta "ares de superioridade" e acaba por converter a infância e a juventude em uma época das "doces asneiras" ou em uma fase que precede "a longa sobriedade das coisas sérias". Além disso, existem aqueles que sequer permitem que esses anos sejam

6 "Experiência. 1. Em seu sentido geral, a experiência é um conhecimento espontâneo ou vivido, adquirido pelo indivíduo ao longo da vida. [...]. 2. Em sentido técnico, a experiência é a ação de observar ou experimentar em vista de formar ou de controlar uma hipótese. Assim, a experiência [...] é o fato de provocar, partindo de condições bem determinadas, uma observação tal que seu resultado seja apto a fazer conhecer a natureza do fenômeno estudado. Sinônimo de experimento." (JAPIASSÚ \& MARCONDES, 1990, p. 92-93). 
vividos, tentando, em nome de uma experiência, empurrá-los, desde já, para a "escravidão da vida" (BENJAMIN, 2009a, p. 21-22).

Na contemporaneidade, as políticas públicas para a infância, em especial, as políticas educacionais, ainda que tentem se desprender de uma concepção de infância conservadora e limitada, onde a criança é entendida como indivíduo despreparado, sem experiência, acrítico, sem cultura e sem história, acabam trazendo consigo essa concepção da experiência adulta como vanguarda. Os adultos sabem o que é melhor para as crianças, sabem o caminho que devem seguir, e as aconselham a pularem etapas, pegarem atalhos, para alcançarem objetivos que sequer construíram por si próprias. A máscara da experiência do adulto cria também para a criança o objetivo, o início, o meio e o fim. Essa concepção, já ultrapassada pelos estudos da infância, coaduna com movimentos e projetos de lei como o Escola Sem Partido, que entendem a criança como propriedade de seus pais e sem qualquer consciência crítica e autonomia de pensamento.

Mas, segundo Benjamin (2009a, p.22), os adultos não percebem que existe outra coisa além da experiência, que existem valores que não se prestam à experiência, valores aos quais nos colocamos a serviço. E, neste sentido, o autor critica: "[...] o filisteu jamais levanta os olhos para as coisas grandiosas e plenas de sentido, a experiência transformou-se em seu evangelho. Ela converte-se para ele na mensagem da vulgaridade da vida". Preso a essa experiência, pois só a conhece, o adulto está também preso ao novo que é sempre o mesmo, que se repete, o que Benjamin chama de "eternamente ontem". E, nesse contexto, a lembrança da infância com sentimentalismo é tida por Benjamin como uma camuflagem para o ódio que os adultos sentem dos sonhos de sua juventude.

Assim, ao mesmo tempo que a experiência pode ser uma vivência significativa, ela pode representar um discurso de autoridade que vai acabar por tentar impedir e deslegitimar a vivência significativa de outrem, no caso, das crianças. O discurso de autoridade dos pais, argumentados a partir de suas vivências, pode representar a invalidação da experiência da de seus filhos e, portanto, de vivências significativas próprias de cada geração.

E é na contramão de tantos estudos na área da infância e da educação, que vem ganhando força, atualmente, na sociedade brasileira, uma concepção de infância já superada por pesquisadores-educadores, na qual a criança é entendida como uma "folha de papel em branco", onde o professor vai depositar o conhecimento e inculcar valores. É neste contexto que ganham forma projetos como o Escola Sem Partido e de Ideologia de Gênero ${ }^{7}$, por exemplo. Argumentos que acusam a escola querer "transformar as crianças em homossexuais" ou os

\footnotetext{
7 Projeto de lei $\mathrm{n}^{\circ}$ 1.859/2015. Acrescenta Parágrafo único ao artigo $3^{\circ}$ da Lei 9.394/96 (Lei de Diretrizes e Bases da Educação), "para prever a proibição de adoção de formas tendentes à aplicação de ideologia de gênero ou orientação sexual na educação". Disponível em: http:/ / www.camara.gov.br/proposicoesWeb/prop_mostrarintegra?codteor=1346799\&filename $=\mathrm{PL}+1859 / 015$. Acesso em 29/3/2018.
} 
concepções de infância e a educação das crianças da classe trabalhadora: uma crítica benjaminiana ao projeto escola sem partido

professores de "doutrinarem as crianças para o comunismo" 8 vem se tornando obstáculos a serem enfrentados pelos profissionais comprometidos com uma Educação pública, plural, laica e democrática, uma educação que tenha como princípio os Direitos Humanos e o pensamento crítico, onde a criança é sujeito social, histórico e cultural e não um mero depósito de informações.

Então, parte-se do pressuposto de que crianças e jovens não são sujeitos que pensam por si e desconsidera-se o fato destes estarem imbricados nas relações como sujeitos históricos, políticos, produtores de conhecimento e cultura. Uma relação entre adultos e crianças fundamentada na "verticalidade". Crianças e jovens seriam vistos como indivíduos passivos e manipuláveis, o que segue na contramão das pesquisas que envolvem infância e juventude, principalmente no campo da educação e da sociologia. "Ninguém educa ninguém, ninguém educa a si mesmo, os homens se educam entre si, mediatizados pelo mundo", já dizia Paulo Freire (2011, p. 71).

Outra questão importante de se destacar é a ideia de que os adultos sabem o que é melhor para as crianças, ou seja, os pais veem a vida de seus filhos como uma propriedade e os tentam privar de toda a sorte de experiências que julgam negativas ou desnecessárias.

É a "experiência como máscara do adulto" trazida por Benjamin. Uma experiência que traz discursos de autoridade, "ares de superioridade" e desvaloriza os anos que crianças e jovens estão vivendo, "converte-os na época das doces asneiras que se cometem na juventude, ou no êxtase infantil que precede a longa sobriedade da vida séria" (BENJAMIN, 2009a, p. 21-22).

Mas, será que em um ponto os pais teriam razão com seus gestos cansados e sua desesperança arrogante? Será necessário que o objeto da nossa experiência seja sempre triste, que não possamos fundar a coragem e o sentido naquilo que não pode ser experimentado? Neste caso então o espírito seria livre. Mas, sempre e sempre, a vida o estaria rebaixando, pois, enquanto soma das experiências, a própria vida seria um desconsolo. (BENJAMIN, 2009a, p.23).

Assim, além da crença de que as crianças e jovens são indivíduos totalmente manipuláveis e passivos, tenta-se, a todo custo, deslegitimar suas experiências.

A partir da construção do conceito de experiência o autor critica a ideia de progresso e desenvolvimento. Não é a quantidade das experiências que nos levará ao desenvolvimento, mas a qualidade e intensidade dessas experiências. A experiência não se funda na razão, mas sim na sensibilidade, na cultura e nas artes.

\footnotetext{
${ }^{8}$ Ideias presentes nos discursos de defesa desses projetos e que se encontra em sites como o da Escola Sem Partido, disponível em: http:/ / escolasempartido.org/, acesso em 18/8/2018.
} 
Segundo Muranaka (2006), o mito mais perigoso e presente na sociedade moderna é o mito do progresso. Benjamin o critica buscando identificar os artifícios discursivos, que visam a alienação; e mostra como o entendimento de progresso iguala a noção do experimentar a uma ilusão. Trata-se de um véu, produzido pelo sistema capitalista, que busca justificar o acúmulo de capital. Somente o discurso científico e técnico, regulamentado pelos interesses da classe dominante, torna capaz e suficiente todo o tipo de apropriação em nome do progresso. Neste sentido, Benjamin trabalha a ideia de progresso como uma ilusão. A ideia de um progresso linear e ascendente fragmenta-se na medida em que está intimamente ligada à ideia de repetição, a repetição no trabalho, a repetição na educação, a repetição no mercado, a repetição no mito.

$\mathrm{Ou}$ seja, no que se refere às políticas educativas, o que conseguimos perceber é uma, ainda, entranhada noção de criança, infância e experiência passiva e intimidada pelo discurso da experiência como autoridade, do desenvolvimento e do progresso. São políticas que trazem uma noção desenvolvimentista da educação e do conhecimento, de escolarização da Educação Infantil como etapa de preparação para o Ensino Fundamental, que por sua vez, seria a preparação para o Ensino Médio, que também seria a preparação para a universidade ou curso técnico ${ }^{9}$, que prepara para o mundo do trabalho. Enfim, anula-se a experiência por si só e a coloca a serviço da vida adulta e de um futuro quase que inalcançável.

Neste contexto, Benjamin (2012a) traz também, mais do que a noção de experiência, mas a pobreza da experiência. A noção de experiência que está perdida no mundo moderno. Essa pobreza da experiência não está apenas em experiências privadas, mas em experiências da humanidade, em geral.

Em seu escrito Experiência e Pobreza (2012a), o autor afirma que "as ações da experiência estão em baixa" e justifica essa pobreza da experiência a partir (1) da tragédia, dor e barbárie, (2) do desenvolvimento da técnica, dos meios de produção e acumulação de capitais e (3) do vazio modo de vida burguês. Essa pobreza da experiência trazida por Benjamin (2012a) não deve ser compreendida como se os homens aspirassem a novas experiências, mas como se quisessem libertar de toda a experiência e aspirar a um mundo em que possam ostentar tão pura e claramente sua pobreza.

É importante ressaltar que essa crítica à pobreza da experiência, pelo autor, está contextualizada na Primeira Guerra Mundial, suas implicações na vida de toda uma geração e seus efeitos no espírito de uma época, onde a experiência é mutilada nos campos de guerra, na tragédia, na fome e na dor. Também se contextualiza em um período de sofisticação dos meios de produção, acumulação de capital e do capitalismo enquanto sistema financeiro, onde o individualismo moderno manifesta-se na redução do homem a uma mercadoria, onde ele se torna um objeto de consumo para o sistema. A capacidade de contemplação do

\footnotetext{
${ }^{9}$ Junto ao movimento conservador se verifica a (re)ascensão de projeto de educação dual, a superior destinada à classe média e elite, a técnica para as classes trabalhadoras.
} 
concepções de infância e a educação das crianças da classe trabalhadora: uma crítica benjaminiana ao projeto escola sem partido

sujeito dilui-se, conforme dilui-se a sua identidade nos meios de produção. Há, desta forma, uma mudança na percepção de mundo e o privado revela-se no material, físico e infinitamente distante do comunitário. Temos, a partir da influência do sistema financeiro, o isolamento e a instalação de uma pobreza de experiência (MURANAKA, 2006).

Larrosa Bondía (2002) também faz algumas considerações acerca da pobreza da experiência nos dias atuais. Para ele, nada mais nos toca e quase nada (de novo) acontece. Muitas coisas se passam, mas a experiência é cada vez mais rara. Assim, ele nos traz o que considera algumas causas e indícios dessa pobreza de experiência. Entre elas estão: (1) o excesso de informação, (2) o excesso de opinião, (3) a falta de tempo e (4) o excesso de trabalho.

Para Larrosa Bondía (2002, p. 21), “a informação não é experiência. E mais, a informação não deixa lugar para a experiência, ela é quase o contrário da experiência, quase uma antiexperiência". Isso porque saber das coisas não significa viver as coisas, saber das coisas não necessariamente nos toca, nada nos acontece.

O autor também acredita que a experiência é cada vez mais rara por excesso de opinião. O sujeito moderno é um sujeito informado que opina sobre tudo o que tem de informação. Para Larrosa Bondía (2002, p. 22):

Em nossa arrogância, passamos a vida opinando sobre qualquer coisa sobre que nos sentimos informados. E se alguém não tem opinião, se não tem uma posição própria sobre o que se passa, se não tem um julgamento preparado sobre qualquer coisa que se lhe apresente, sente-se em falso, como se lhe faltasse algo essencial. E pensa que tem de ter uma opinião. Depois da informação, vem a opinião. No entanto, a obsessão pela opinião também anula nossas possibilidades de experiência, também faz com que nada nos aconteça.

A falta de tempo também colabora para a pobreza da experiência. Tudo passa depressa e isso torna as coisas fugazes e instantâneas. Assim, a velocidade em que temos contato com tudo faz com que não haja vivências significativas e, desta forma, estamos sempre buscando o novo. "O sujeito moderno não só está informado e opina, mas também é um consumidor voraz e insaciável de notícias, de novidades, um curioso impenitente, eternamente insatisfeito". A velocidade e o que ela provoca, a falta de silêncio e de memória, são também inimigas mortais da experiência (BONDÍA, 2002, p. 23).

Larrosa Bondía (2002) chama atenção para um equívoco bastante comum: o de confundir experiência com trabalho. Na realidade, ele faz uma crítica ao excesso de trabalho como prejudicial à experiência. Ou seja, o que entendemos como o trabalho sob a ótica do capital, que aliena e segrega mulheres e homens do que é produzido. O sujeito moderno nunca para e isso impede que algo lhe aconteça. Ele se relaciona com o acontecimento do ponto de vista da ação. Sempre se perguntando o que pode fazer. Sempre está desejando fazer, produzir 
e regular algo. O sujeito moderno está atravessado por vontade de mudar as coisas, de fazer algo de forma prática.

Por isso, nas palavras de Walter Benjamin (2012a, p.128), "ficamos pobres. Abandonamos uma depois da outra todas as peças do patrimônio humano, tivemos que empenhá-la muitas vezes a um centésimo do seu valor para recebermos em troca a moeda miúda do atual".

Entendemos que o cenário apresentado por Larrosa Bondía (2002) afeta a criança e as concepções de infância. A velocidade das informações, o excesso de opinião, excesso de trabalho, tudo isso influencia a vida das crianças e as políticas educacionais para esta população etária. As crianças estão imersas neste mundo, ao passo que compartilham dele, tem contato com conhecimentos já existentes e produzem novos conhecimentos. Assim, as crianças estão cada vez mais imersas em um mundo em que a experiência se torna uma raridade. As crianças são envolvidas na trama ideológica da mídia e do marketing infantil, do mundo do trabalho e da informação, exige-se delas cada vez mais atitudes práticas e posicionamentos perante a sociedade, pautados no consumismo e produtivismo. As políticas educacionais veem a educação de crianças como uma preparação para seu futuro, como uma fábrica onde estas crianças serão moldadas.

Desta forma, a noção de experiência em Benjamin (2009a, 2012a), bem como o que o autor nos traz sobre o que julga se tratar de uma pobreza da experiência, e as articulações e críticas que faz à sofisticação e desenvolvimento do capitalismo e do sistema financeiro e seus impactos na sociedade, nos ajudam a pensar educação, a pensar infância e podem nos ajudar a compreender o projeto de educação para as classes populares que está em pauta na contemporaneidade. Neste contexto, a quais interesses servem as políticas educacionais? O que está reservado para as crianças da classe trabalhadora?

\section{A educação das crianças da classe trabalhadora}

É latente nas obras de Walter Benjamin suas fortes críticas ao capitalismo e suas consequências para a Educação, com destaque à educação da classe proletária.

Segundo Muranaka (2006), a elaboração da sociedade e Estado burgueses produz uma geração de desacreditados. A figura do filisteu, trazida em Benjamin, representa o adulto em oposição ao jovem e à criança. Representa, também, o detentor dos meios de produção, que restringe as possibilidades de experiências do jovem e da criança ao "industrializar" a educação, segundo regras e leis de mercado, transformando-os em futuros produtos que devem atender à sociedade burguesa. 
concepções de infância e a educação das crianças da classe trabalhadora: uma crítica benjaminiana ao projeto escola sem partido

Benjamin (2009c) acredita que a educação proletária deve ser construída pela consciência de classe ${ }^{10}$. E para ele, muito antes que as crianças possam ser instruídas de uma forma proletária, elas precisam ser educadas proletariamente, ou seja, educadas dentro de sua classe social e para sua classe social, considerando esse viés de classe, fora, assim, da concepção burguesa de educação. Isso porque a burguesia possui seu sistema educacional e a educação burguesa das crianças menores está em consonância com a situação dessa classe. Seus conteúdos fracassam no que se refere, principalmente à pequena infância, por sua desumanidade.

E é nesse sentido que é possível encontrar atritos e dissonâncias entre a concepção de educação proposta pelo projeto Escola Sem Partido e o tipo de pedagogia classista proposta por Benjamin. O movimento e, por conseguinte, o projeto de lei exigem uma educação acrítica e falaciosamente neutra, mas militam por uma educação burguesa para a classe trabalhadora, negligenciando e, inclusive, criminalizando qualquer forma de transgressão.

Assim, para Benjamin (2009c, p.113), a educação proletária precisa se diferenciar da educação burguesa, especialmente, pelo contexto, fugindo dos métodos psicologizantes. Inclusive, ele salienta que esse interesse pelo método é algo tipicamente burguês. "A educação proletária necessita, portanto, primeiramente de um contexto, um terreno objetivo no qual se educa. Não necessita de uma ideia para a qual se educa".

Para o autor (2009c), a criança proletária nasce dentro de sua classe e é essa situação de classe que vai determinar aquilo que ela irá se tornar e não qualquer meta educacional doutrinária. Neste sentido, a educação tem, na luta de classes, papel de aguçar sua consciência, transformando-a, então, em "consciência de classe", e colocar a avaliação completa do meio social a serviço de metas revolucionárias.

A pedagogia burguesa tem como alicerces a psicologia e a ética e, neste contexto, proclama uma essência absoluta da infância, assim como uma essência de ser humano ou de cidadão. Máscaras que escondem o real caráter da educação burguesa: preservar o status quo.

Desta forma, Benjamin (2009c, p.114) acredita que é a partir do teatro proletário infantil que a criança proletária tem seu lugar de educação dialeticamente determinado. Esse teatro em nada tem a ver com o da burguesia. Ao contrário, a amedronta, pois possibilita "ver a força mais poderosa do futuro ser despertada nas crianças".

No teatro proletário infantil o enfoque está no processo, nas tensões que se desenrolam nas encenações e essas tensões são os verdadeiros educadores, não

10 Walter Benjamin, sob forte influência de Karl Marx, demonstra entender o conceito de consciência de classe como a compreensão das crenças e atitudes através de sua classe social ou condição econômica, ou seja, levando em consideração os interesses de sua classe social. Benjamin não desenvolveu o conceito de consciência de classe ou luta de classes especificamente, mas em algumas obras como as Teses sobre o conceito de História, de 1940, Programa de um Teatro Infantil Proletário, de 1928, Infância em Berlim por volta de 1900, ele traz ideias sobre esses conceitos e insere as crianças em uma trama em que o viés de classe tem papel central. 
havendo preocupação com influenciar as crianças em sentido imediato, principalmente no que se refere a sua personalidade moral, como é de praxe no teatro burguês.

Os teatros infantis proletários exigem uma coletividade, exigiriam a classe. Para o autor (2009c), apenas a classe operária possibilita a existência de coletividades, como as assembleias populares, por exemplo, e, considerando que a criança também constitui uma coletividade, faz-se necessário a classe operária prestar atenção na coletividade infantil. Assim, o diretor do teatro infantil proletário tem como fundamento a observação, abrindo mão da superioridade intelectual e moral, bem como do método da correção, tipicamente burgueses.

Ainda em Walter Benjamin, encontramos a defesa de que a pedagogia proletária garante às crianças a realização de sua infância, uma vez que não há preocupação com desempenho, mas com as próprias vivências, as tensões e a coletividade. Entretanto, não necessariamente precisa estar descolada do espaço das lutas de classes. De maneira lúdica os conteúdos podem encontrar lugar neste espaço sem precisar subjugar a sugestionabilidade infantil, sem assumir um domínio formal sobre as crianças. Nas palavras de Benjamin (2009c, p. 118), não se necessita "daquelas milhares de palavrinhas com as quais a burguesia mascara a luta de classes de sua pedagogia. Poder-se-á renunciar assim tanto às práticas 'imparciais', 'compreensivas', 'sensíveis', como também às educadoras 'cheias de amor pela criança'".

Portanto, em uma educação proletária, é importante que se considere não apenas a criança, a "natureza infantil", mas a sua situação de classe, situação em que se encontra totalmente negligenciada pelo sistema escolar burguês.

E, para darmos conta deste debate, é importante considerar a concepção burguesa de educação utilitária, totalmente voltada para o mundo do trabalho. Qualquer tipo de educação que se pretenda libertária e emancipatória para a classe trabalhadora, não se resumindo à aquisição de uma técnica a ser utilizada no mundo profissional, sofrerá ataques. E o Escola Sem Partido é um ataque a qualquer forma de pensamento crítico que envolva a conscientização, organização e emancipação da classe trabalhadora. O Escola Sem Partido é um signo da luta de classes.

Neste sentido, podemos pensar com Benjamin (2009b, p.33) quando ele destaca que "as ciências, no desenvolvimento do seu aparato profissionalizante, foram desviadas de sua origem comum fundada na ideia do saber". Sobre a ciência e, por conseguinte a escola, e sua preparação para o mundo do trabalho, o autor afirma que "para a grande maioria dos estudantes, a ciência é uma escola profissionalizante" e ela deve moldar com exclusividade a vida de quem a segue. "Entre as reservas mais inocentes e mentirosas que se tem perante ela, encontrase a expectativa de que ela deva ajudar este ou aquele a se prepararem para uma profissão". (BENJAMIN, 2009b, p.32). Dessa forma, traça-se uma concepção de educação deturpada e desconsidera-se o que profissionais, estudiosos e pesquisadores da área já acumularam sobre o assunto: a educação como criação 
concepções de infância e a educação das crianças da classe trabalhadora: uma crítica benjaminiana ao projeto escola sem partido

de possibilidades ao pensar e o novo e reinventar a própria educação, a educação como uma possibilidade de transformação social.

Podemos dizer, nesse sentido, que "a função do docente no ato de ensinar tem implícito o ato de educar". É esse ato de educar que é alvo do conservadorismo das elites empresariais e de grupos políticos religiosos através de seus intelectuais e parlamentares comprometidos com o atraso em termos inquisitoriais. "A pedagogia da confiança e do diálogo crítico são substituídos pelo estabelecimento de uma nova função: estimular alunos e seus pais a se tornarem delatores". Isto porque incomoda aos setores conservadores do país que o ato de educar seja um "confronto de visões de mundo, de concepções científicas e de métodos pedagógicos, desenvolver a capacidade de ler criticamente a realidade e constituírem-se sujeitos autônomos" (FRIGOTTO, 2017, p. 31).

É um equívoco acreditar que o ato de educar se resuma a uma mera transmissão de conhecimentos, sem, inclusive, refletir também sobre o conceito de conhecimento e o conceito de educação. Também é um equívoco negligenciar a produção de conhecimento, história e cultura das crianças e dos jovens em nossa sociedade. É negligenciar a luta incessante por uma horizontalidade das relações entre adultos, jovens e crianças dentro e fora dos espaços escolares. Por fim, é equivocado pensar que, em uma sociedade capitalista onde as grandes corporações, inclusive e principalmente midiáticas, estão a serviço do capital e da manutenção do sistema vigente, alguns professores de pensamento crítico, que proponham um questionamento sobre este estado de coisas, estejam do lado mais forte da corda, em um "cabo de guerra" da luta de classes. Trata-se de um discurso fantasioso e falacioso envolvendo uma neutralidade intocável, como se o que estivesse em jogo não fosse exatamente o oposto.

\section{Algumas considerações}

Ainda que timidamente, nos propusemos aqui, como ponto de partida, pensar a infância, a educação das crianças da classe trabalhadora e o projeto Escola Sem Partido, a partir das ideias de Walter Benjamin. Na realidade, trata-se de um ensaio inicial sobre o assunto que possa ajudar a pensar sobre o crescimento do conservadorismo nas escolas brasileiras e na educação das nossas crianças. Nossa intenção não é esgotar esta articulação nesse artigo, mas tentar contribuir e abrir possibilidades outras.

Para nós, projetos de lei e movimentos conservadores como o Escola Sem Partido, que interferem no currículo escolar, ameaçam a autonomia docente, demonizam professores, subestimam crianças e jovens, convocam pais como fiscalizadores do trabalho docente e colocam em risco a gestão democrática, são uma ameaça à educação libertária e emancipatória pela qual sempre lutamos. A criança não é apenas um depósito de informações e nem o professor é apenas um transmissor de conhecimentos. 
Nas obras de Benjamin, a criança aparece como sujeito, produtor de história e cultura e o autor traz como crítica qualquer discurso de autoridade que deslegitime a sua experiência. Além disso, Benjamin critica fortemente a concepção burguesa de educação que, ao seu entender, acaba por cercear as crianças da classe trabalhadora, trazendo para a educação um viés de classe como requisito para a autonomia e emancipação.

É bem verdade que Walter Benjamin foi um filósofo e escritor do final do século XIX e início do século XX e que suas obras estão localizadas em um espaçotempo bastante específico: Alemanha, Segunda Guerra Mundial, expansão do nazismo na Europa. Entretanto, é impossível negar que seus escritos não nos pareçam profundamente atuais. As suas considerações acerca da experiência (2009a) e da pobreza da experiência (2012a), as críticas ao sistema capitalista, ao estilo de vida burguês e ao enclausuramento das crianças da classe proletária em um sistema educacional burguês que não lhes proporciona "a realização de sua infância", nos ajuda a pensar as relações nos tempos atuais e, por conseguinte, infância e educação.

Benjamin $(2009,2012)$ não elaborou exatamente uma teoria da infância e ela, bem como outros conceitos, aparece em seus escritos de forma um pouco fragmentada, sendo, por sua vez, necessário adentrar suas obras para buscar essas noções. Entretanto, torna-se quase inevitável apreciar algumas das obras de Benjamin e sermos levados a pensar sobre a educação das crianças e jovens, sobre o crescimento do conservadorismo e programas como o Escola Sem Partido, bem como políticas outras, que afetam tão diretamente a educação das crianças e dos profissionais da educação. E é neste sentido que Walter Benjamin pode nos ajudar a pensar a infância e a educação e a desenvolver pesquisas importantes neste campo, embasando professores-pesquisadores no enfrentamento ao retrocesso no que se refere aos direitos dos trabalhadores e das crianças pequenas frente aos interesses do capital. Trata-se de um contexto de luta, resistência e militância pelas crianças pequenas e pelo que entendemos como educação de qualidade.

\section{referências}

AGAMBEN, Giorgio. Ensaio sobre a destruição da experiência. In: AGAMBEN, Giorgio. Infância e História. Destruição da experiência e origem da história. Belo Horizonte: Editora UFMG, 2008, p. 19-78.

BENJAMIN, Walter. Experiência. In: Reflexões sobre a criança, o brinquedo e a educação. Ed.34. 2009a. 21-25.

. A vida dos estudantes. In: Reflexões sobre a criança, o brinquedo e a educação. Ed.34. 2009b. 31-48.

Programa de um teatro infantil proletário. In: Reflexões sobre a criança, o brinquedo e a educação. Ed.34. 2009c. 111-120.

Pedagogia Comunista. In: Reflexões sobre a criança, o brinquedo e a educação. Ed.34. 2009d. 121-126. 
concepções de infância e a educação das crianças da classe trabalhadora: uma crítica benjaminiana ao projeto escola sem partido

. Experiência e Pobreza. In: Obras escolhidas I: magia e técnica, arte e politica: ensaios sobre literatura e história da cultura. São Paulo, Ed. Brasiliense. 2012a. 123-128.

O narrador: contribuições sobre a obra de Nikolai Leskov. In: Obras escolhidas I: magia e técnica, arte e política: ensaios sobre literatura e história da cultura. São Paulo, Ed. Brasiliense. 2012b. 213-240.

. A hora das crianças. Narrativas radiofônicas. Tradução Aldo Medeiros. Rio de Janeiro: NAU Editora, 2015.

BONDÍA, Jorge Larrosa. Notas a experiência e o saber de experiência. In Revista Brasileira de Educação. N $\mathrm{N}^{\mathrm{a}}$ 19. 2002. Disponível em http://www.scielo.br/pdf/rbedu/n19/n19a02.pdf. Acesso em 5/4/2010.

DELEUZE, Gilles. Empirismo e subjetividade. Tradução Luiz Orlandi. Rio de Janeiro: Ed. 34, 2001

. Diferença e repetição. $1^{\text {a }}$ ed. Rio de Janeiro: Graal, 1988.

FOUCAULT, Michel. História da Sexualidade. O Uso dos Prazeres, Vol. II Rio de Janeiro: Graal, 1984.

- Problematização do sujeito: psicologia, psiquiatria e psicanálise (Ditos e escritos Vol. I). Rio de Janeiro: Forense Universitária, 1999.

FREIRE, Paulo. Pedagogia do Oprimido. Rio de Janeiro: Ed. Paz e Terra, 2011.

FRIGOTTO, Gaudêncio. (org). Escola Sem Partido: esfinge que ameaça a educação e a sociedade brasileira. Rio de Janeiro: UERJ, LPP, 2017. 144p.

JAPIASSÚ, H.; MARCONDES, D. Dicionário básico de filosofia. Rio de Janeiro: Jorge Zahar Editor, 1990.

LESSA, Juliana Schumacker. O conceito de experiência em Walter Benjamin: elementos para pensar a educação na infância. In Revista Zero a seis. v. 18, n. 33 p. 108-121. Florianópolis. Jan-jun/2016. 108-121p. Disponível em https:// periodicos.ufsc.br/index.php/zeroseis/article/view/19804512.2016v18n33p108/31492. Acesso em 10/05/2018.

LÖWY, Michael. O ponto de vista dos vencidos na história da América Latina: reflexões metodológicas a partir de Walter Benjamin. In: As aventuras de Karl Marx contra o Barão de Müchhausen. Marxismo e positivismo na sociologia do conhecimento. $9^{a}$ edição revista e ampliada. São Paulo: Cortez, 2009.

MURANAKA, Fabiana. Referências sobre o conceito de experiência em Walter Benjamin. In XI Seminário Internacional de Educação. Formação de Professores: A prática pedagógica e o trabalho na diversidade. ULBRA, Cachoeira do Sul/RS 2006. Disponível em www.sieduca.com.br/2006/admin/upload/73.doc. Acesso em $5 / 2 / 2018$.

PENNA, Fernando de Araújo. O Escola Sem Partido como chave de leitura do fenômeno educacional. In: FRIGOTTO, Gaudêncio. (org). Escola Sem Partido: esfinge que ameaça a educação e a sociedade brasileira. Rio de Janeiro: UERJ, LPP, 2017. p 3548.

recebido em: 15.07 .2018

aprovado em: 31.08 .2018 